Jurnal Ilmiah Matematika dan Pendidikan Matematika (JMP)

Vol. 12 No. 2, Desember 2020, Hal. 63-79

ISSN (Cetak) : 2085-1456; ISSN (Online) : 2550-0422

\title{
APLIKASI TRAVELLING SALESMAN PROBLEM PADA PENGEDROPAN BARANG DI ANJUNGAN MENGGUNAKAN METODE INSERTION
}

\author{
Priska Sari Dewi \\ Jurusan Matematika, FMIPA Universitas Jenderal Soedirman \\ priska.saridewi@gmail.com \\ Triyani \\ Jurusan Matematika, FMIPA Universitas Jenderal Soedirman \\ Siti Rahmah Nurshiami \\ Jurusan Matematika, FMIPA Universitas Jenderal Soedirman
}

\begin{abstract}
Travelling Salesman Problem (TSP) is a problem to find the shortest path a salesman visits all the cities exactly once, and returns to the starting city. In this reseacrh, the methods for TSP used are the nearest insertion method, the cheapest insertion method, and the farthest insertion method. The program for deciding the minimum TSP from three insertion methods was created with the help of the function of Software R. The TSP using three insertion methods do not always have the same weight and route.
\end{abstract}

Key words: Travelling Salesman Problem, Nearest Insertion Method, Cheapest Insertion Method, Farthest Insertion Method, and Software R.

ABSTRAK. Travelling Salesman Problem (TSP) merupakan permasalahan mencari lintasan terpendek seorang salesman harus mengunjungi semua kota yang akan dituju tepat satu kali, dan kembali ke kota awal. Pada penelitian ini, penyelesaian TSP menggunakan metode nearest insertion, metode cheapest insertion, dan metode farthest insertion. Program minimum TSP dari ketiga metode dibuat dengan bantuan fungsi Software $R$. Hasil TSP dengan menggunakan tiga metode insertion tidak selalu menghasilkan bobot dan rute lintasan yang sama namun bergantung pada data yang digunakan.

Kata kunci: Travelling Salesman Problem, Metode Nearest Insertion, Metode Cheapest Insertion, Metode Farthest Insertion, dan Software R.

\section{PENDAHULUAN}

Anjungan lepas pantai mempunyai peran dan fungsi dalam kegiatan eksplorasi bahan tambang. Tercukupinya kebutuhan barang pada anjungan lepas pantai menjadi salah satu pendukung utama jalannya kegiatan eksplorasi. Pengedropan barang pada anjungan lepas pantai melalui jalur laut dari sumber ke 
titik tujuan menggunakan rute terpendek. Masalah rute pengedropan barang dari titik awal menuju tempat tujuan tepat sekali dan kembali ke titik awal sering disebut dengan Travelling Salesman Problem (Rosenkrantz dkk, 1977).

Travelling Salesman Problem (TSP) dikemukakan pada tahun 1800-an oleh dua orang matematikawan, Irlandia William Rowan Hamilton dan Thomas Penyngton Kirkman. Masalah ini dapat direpresentasikan sebagai sikel terpendek dari sebuah graf lengkap dengan $n$ titik pada masalah pencarian rute optimum suatu perjalanan pengiriman barang dari suatu sumber ke tujuan. Permasalahan ini menjadi sangat kompleks ketika 100 atau lebih kota yang harus dikunjungi.

Banyak peneliti telah mengkaji penyelesaian Travelling Salesman Problem, namun sampai saat ini penyelesaian Travelling Salesman Problem masih belum menghasilkan solusi yang optimal. Salah satunya yaitu Hahsler \& Hornik (2007) yang telah mengkaji metode insertion untuk tiga metode yaitu metode nearest insertion, metode cheapest insertion dan metode farthest insertion untuk menyelesaikan Travelling Salesman Problem dengan menggunakan matriks jarak namun tidak dijelaskan secara terperinci. Untuk itu dalam penelitian ini, akan dikaji penyelesaian Travelling Salesman Problem dengan menggunakan metode insertion secara rinci untuk ketiga metode yaitu metode nearest insertion, metode cheapest insertion dan metode farthest insertion. Ketiga metode ini digunakan untuk menyelesaikan Travelling Salesman Problem dengan mengambil $n$ data jarak koordinat antar titik. Selanjutnya menyusun program minimum dari ketiga metode insertion menggunakan bantuan fungsi Software $R$.

\section{METODE PENELITIAN}

Penelitian ini dilakukan dengan perangkat keras laptop individu dengan Prosesor Intel ${ }^{\circledR}$ Core $^{\mathrm{TM}}$ i5-8250U CPU @1.60GHz, perangkat lunak dengan Sistem Operasi Windows 10 Home 64-bit, Studio $R$ Version 1.3.1093, dan Microsoft Excel 2019 Profesional Plus. Data yang digunakan adalah data jarak koordinat antar titik dalam bentuk file penyimpanan File Comma Separated Values (CSV). Adapun langkah-langkah yang dilakukan dalam penelitian ini adalah mengkaji dan menyelesaikan TSP menggunakan metode nearest insertion, 
metode cheapest insertion, dan metode farthest insertion menggunakan data jarak koordinat antar titik dan membuat program software $R$ untuk meminimumkan TSP dari metode nearest insertion, metode cheapest insertion, dan metode farthest insertion.

\section{HASIL DAN PEMBAHASAN}

Persoalan Travelling Salesman Problem dapat direpresentasikan untuk menentukan sirkuit Hamilton yang memiliki bobot minimum pada graf lengkap $\left(K_{n}\right)$ berbobot dengan $n$ titik (Munir, 2010). Titik pada graf lengkap dapat berupa koordinat kartesius, sehingga jarak (d) antara dua buah titik $\left(x_{1}, y_{1}\right)$ dan $\left(x_{2}, y_{2}\right)$ harus dihitung secara Euclidean dengan persamaan

$$
d=\sqrt{\left(x_{1}-x_{2}\right)^{2}+\left(y_{1}-y_{2}\right)^{2}} .
$$

Secara nyata, sampai saat ini penyelesaian Travelling Salesman Problem masih belum menghasilkan solusi yang optimal. Salah satu algoritma yang digunakan dalam penyelesaian Travelling Salesman Problem adalah algoritma heuristic (Rosenkrantz, Stearns, \& Lewis, 1977). Metode heuristic memberikan pendekatan dalam menyelesaikan permasalahan optimasi kombinatorial di mana diperoleh hasil yang mungkin dan mendekati optimal (Hansler \& Kornik, 2007).

Menurut Daniel dkk (1977), konsep metode insertion dalam menyelesaikan TSP adalah membangun tour dari himpunan kota atau subtour dengan cara memasukkan sebuah kota ke kota asal sehingga menjadi subtour, dan berulang sampai semua kota terhubung. Diberikan graf TSP $(N, d)$ dimana $N$ merepresentasikan jumlah kota dan $d$ merepresentasikan jarak antar kota. Sebuah tour $T$ pada subset dari $N$ disebut subtour dari $(N, d)$ dimana $a \in T$ berarti $a \in N$. Sebuah subtour $T$ dan sebuah kota $k$ di $N$ tetapi tidak ada di $T$, didefiniskan $\operatorname{TOUR}(T, k)$, dan akan menjadi sebuah subtour dengan ketentuan berikut :

a. Jika subtour $T$ melewati lebih dari 1 kota, maka

1) mencari sisi $(i, j)$ di $T$ yang meminimalkan

$$
F=d(i, k)+d(k, j)-d(i, j)
$$

$F:$ Jarak tambahan $i$ : Kota pertama dalam insertion

$k:$ Kota yang belum terpilih $j:$ Kota kedua dalam insertion 
2) menghapus sisi $(i, j)$ dan menambahkan sisi $(i, k)$ dan $(k, j)$ untuk memperoleh $\operatorname{TOUR}(T, k)$

b. Jika subtour $T$ melewati satu kota $i$ saja maka, untuk membuat $\operatorname{TOUR}(T, k)$ dengan 2 kota, digunakan 2 buah arc (himpunan dari pasangan terurut $i, j$ yang mempunyai arah dari titik $i$ ke $j)$ yaitu $\operatorname{arc}(i, j)$ dan $\operatorname{arc}(j, i)$ yang didefinisikan sebagai $(i, j) \rightarrow(j, i)$, yang berarti terdapat lintasan dari kota $i$ ke $j$ begitupun sebaliknya.

\subsection{Penyelesaian TSP dengan Metode Nearest Insertion}

Metode nearest insertion yaitu metode menyisipkan kota terdekat dari suatu kota yang sudah termuat pada subtour yang sudah ada untuk masuk ke dalamnya sampai seluruh kota terhubung (Yuan Ze University, 2015). Berikut diagram alir langkah metode nearest insertion.

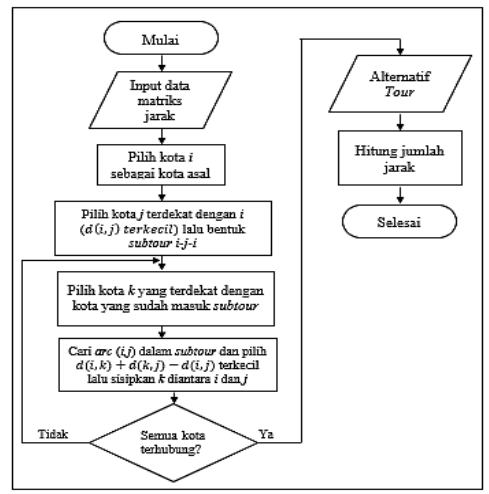

Gambar 1. Diagram Alir Metode Nearest Insertion

Berikut diberikan contoh penyelesaian TSP dengan menggunakan Metode Nearest Insertion. Misal diberikan data koordinat 14 anjungan seperti pada Tabel 1.

Tabel 1. Data Koordinat 14 Anjungan

\begin{tabular}{crr|crr} 
Kota & \multicolumn{1}{c|}{ x } & \multicolumn{1}{c|}{ y } & Kota & \multicolumn{1}{c}{ x } & \multicolumn{1}{c}{} \\
\hline A & 14 & 8 & H & 4 & 17 \\
B & 9 & 4 & I & 12 & 8 \\
C & 6 & 18 & J & 19 & 16 \\
D & 17 & 13 & K & 7 & 9 \\
E & 7 & 5 & L & 4 & 7 \\
F & 3 & 10 & M & 10 & 16 \\
G & 11 & 9 & N & 8 & 4
\end{tabular}


Jarak antar anjungan dalam bentuk koordinat diubah ke dalam jarak Euclidean menggunakan Persamaan (1) dan dapat dilihat pada Tabel 2 berikut.

Tabel 2. Jarak Euclidean 14 Anjungan

\begin{tabular}{|c|c|c|c|c|c|c|c|c|c|c|c|c|c|c|}
\hline & A & B & C & D & $E$ & $F$ & G & $H$ & 1 & J & K & L & M & $\mathrm{N}$ \\
\hline A & 0 & 6,403124 & 12,806248 & 5,830952 & 7,615773 & 11,18034 & 3,162278 & 13,453624 & 2 & 9,433981 & 7,071068 & 10,049876 & 8,944272 & 7,211103 \\
\hline B & 6,403124 & 0 & 14,317821 & 12,041595 & 2,236068 & 8,485281 & 5,385165 & 13,928388 & 5 & 15,620499 & 5,385165 & 5,830952 & 12,041595 & 1 \\
\hline C & 12,806248 & 14,317821 & & 12,083046 & 13,038405 & 8,544004 & 10,29563 & 2,236068 & 11,661904 & 13,152946 & 9,055385 & 11,18034 & 4,472136 & 14,142136 \\
\hline D & 5,830952 & 12,041595 & 12,083046 & 0 & 12,806248 & 14,317821 & 7,211103 & 13,601471 & 7,071068 & 3,605551 & 10,77033 & 14,317821 & 7,615773 & 12,727922 \\
\hline$E$ & 7,615773 & 2,236068 & 13,038405 & 12,806248 & 0 & 6,403124 & 5,656854 & 12,369317 & 5,830952 & 16,278821 & 4 & 3,605551 & 11,401754 & 1,414214 \\
\hline F & 11,18034 & 8,485281 & 8,544004 & 14,317821 & 6,403124 & 0 & 8,062258 & 7,071068 & 9,219544 & 17,088007 & 4,123106 & 3,162278 & 9,219544 & 7,81025 \\
\hline G & 3,162278 & 5,385165 & 10,29563 & 7,211103 & 5,656854 & 8,062258 & 0 & 10,630146 & 1,414214 & 10,630146 & 4 & 7,28011 & 7,071068 & 5,830952 \\
\hline H & 13,453624 & 13,928388 & 2,236068 & 13,601471 & 12,369317 & 7,071068 & 10,630146 & 0 & 12,041595 & 15,033296 & 8,544004 & 10 & 6,082763 & 13,601471 \\
\hline I & 2 & 5 & 11,661904 & 7,071068 & 5,830952 & 9,219544 & 1,414214 & 12,041595 & 0 & 10,630146 & 5,09902 & 8,062258 & 8,246211 & 5,656854 \\
\hline J & 9,433981 & 15,620499 & 13,152946 & 3,605551 & 16,278821 & 17,088007 & 10,630146 & 15,033296 & 10,630146 & 0 & 13,892444 & 17,492856 & 9 & 16,278821 \\
\hline K & 7,071068 & 5,385165 & 9,055385 & 10,77033 & 4 & 4,123106 & 4 & 8,544004 & 5,09902 & 13,892444 & 0 & 3,605551 & 7,615773 & 5,09902 \\
\hline L & 10,049876 & 5,830952 & 11,18034 & 14,317821 & 3,605551 & 3,162278 & 7,28011 & 10 & 8,062258 & 17,492856 & 3,605551 & 0 & 10,816654 & 5 \\
\hline M & 8,944272 & 12,041595 & 4,472136 & 7,615773 & 11,401754 & 9,219544 & 7,071068 & 6,082763 & 8,246211 & 9 & 7,615773 & 10,816654 & 0 & 12,165525 \\
\hline N & 7,211103 & 1 & 14,142136 & 12,727922 & 1,414214 & 7,81025 & 5,830952 & 13,601471 & 5,656854 & 16,278821 & 5,09902 & 5 & 12,165525 & 0 \\
\hline
\end{tabular}

Selanjutnya penyelesaian TSP dilakukan dengan langkah-langkah berikut.

Langkah 1 Pada pembahasan kali ini dipilih anjungan C sebagai anjungan asal.

Langkah 2 Anjungan $\mathrm{H}$ terpilih sebagai anjungan terdekat dengan anjungan $\mathrm{C}$ karena memiliki jarak yang paling minimum yaitu 2,236068. Subtour sementara $C-H-C$ atau dapat ditulis $(C, H) \rightarrow(H, C)$.

Langkah 3 Berikut ditunjukkan jarak antar anjungan dengan anjungan $\mathrm{C}$ dan $\mathrm{H}$.

Tabel 3. Anjungan Terdekat Penambah Subtour Pertama Metode Nearest Insertion

\begin{tabular}{|c|c|c|c|c|c|}
\hline Jarak dari & $\mathrm{Ke}$ & Jarak & Jarak dari & $\mathrm{Ke}$ & Jarak \\
\hline $\mathrm{C}$ & $\mathrm{A}$ & 12,8062 & $\mathrm{H}$ & $\mathrm{A}$ & 13,4536 \\
\hline $\mathrm{C}$ & B & 14,3178 & $\mathrm{H}$ & B & 13,9284 \\
\hline $\mathrm{C}$ & $\mathrm{D}$ & 12,083 & $\mathrm{H}$ & $\mathrm{D}$ & 13,6015 \\
\hline $\mathrm{C}$ & E & 13,0384 & $\mathrm{H}$ & $\mathrm{E}$ & 12,3693 \\
\hline $\mathrm{C}$ & $\mathrm{F}$ & 8,544 & $\mathrm{H}$ & F & 7,07107 \\
\hline $\mathrm{C}$ & G & 10,2956 & $\mathrm{H}$ & G & 10,6301 \\
\hline $\mathrm{C}$ & I & 11,6619 & $\mathrm{H}$ & I & 12,0416 \\
\hline $\mathrm{C}$ & $\mathrm{J}$ & 13,1529 & $\mathrm{H}$ & $\mathrm{J}$ & 15,0333 \\
\hline $\mathrm{C}$ & K & 9,05539 & $\mathrm{H}$ & K & 8,544 \\
\hline $\mathrm{C}$ & $\mathrm{L}$ & 11,1803 & $\mathrm{H}$ & $\mathrm{L}$ & 10 \\
\hline $\mathrm{C}$ & $\mathrm{M}$ & 4,47214 & $\mathrm{H}$ & M & 6,08276 \\
\hline $\mathrm{C}$ & $\mathrm{N}$ & 14,1421 & $\mathrm{H}$ & $\mathrm{N}$ & 13,6015 \\
\hline
\end{tabular}


P. S. Dewi et al.

Melihat Tabel 3, terpilih anjungan M sebagai anjungan terdekat dengan anjungan C karena memiliki jarak paling minimum yaitu 4,472136, lalu anjungan $\mathrm{M}$ disisipkan dalam subtour dan dihitung menggunakan Persamaan (2) yang menghasilkan jarak tambahan terkecil.

Tabel 4. Arc Penambah Subtour Pertama pada Metode Nearest Insertion

\begin{tabular}{ccc} 
Arc awal & $\begin{array}{c}\text { Arc yang akan ditambahkan } \\
\text { ke subtour }\end{array}$ & Jarak tambahan \\
\hline$(C, H)$ & $(C, M) \rightarrow(M, H)$ & $d_{C M}+d_{M H}-d_{C H}=8,318831$ \\
$(H, C)$ & $(H, M) \rightarrow(M, C)$ & $d_{H M}+d_{M C}-d_{H C}=8,318831$
\end{tabular}

Melihat Tabel 4, dipilih $\operatorname{arc}(C, M)$ dengan $\operatorname{arc}(M, H)$ menggantikan $\operatorname{arc}(C, H)$ dengan jarak tambahan sebesar 8,318831. Subtour sementara yaitu $(C, M) \rightarrow$ $(M, H) \rightarrow(H, C)$. Belum semua anjungan masuk subtour, maka kembali seperti Langkah 3. Adapun hasil langkah berikutnya ada pada Tabel 5 berikut.

Tabel 5. Penambah Subtour pada Metode Nearest Insertion

\begin{tabular}{|c|c|c|c|c|}
\hline Langkah & $\begin{array}{l}\text { Tambahan } \\
\text { anjungan }\end{array}$ & $\begin{array}{l}\text { Terdekat } \\
\text { dari }\end{array}$ & $\begin{array}{c}\text { Jarak } \\
\text { tambahan }\end{array}$ & Subtour sementara \\
\hline 4 & $\mathrm{G}$ & M & 7,071068 & $\begin{aligned}(C, M) \rightarrow(M, G) & \rightarrow(G, H) \\
& \rightarrow(H, C)\end{aligned}$ \\
\hline 5 & I & G & 2,589357 & $\begin{array}{l}(C, M) \rightarrow(M, I) \rightarrow(I, G) \rightarrow \\
(G, H) \rightarrow(H, C)\end{array}$ \\
\hline 6 & $\mathrm{~A}$ & I & 2,698061 & $\begin{array}{l}(C, M) \rightarrow(M, I) \rightarrow(I, G) \rightarrow \\
(G, H) \rightarrow(H, C)\end{array}$ \\
\hline 7 & $\mathrm{~K}$ & $\mathrm{G}$ & 1,913858 & $\begin{array}{l}(C, M) \rightarrow(M, A) \rightarrow(A, I) \rightarrow \\
(I, G) \rightarrow(G, K) \rightarrow(K, H) \rightarrow(H, C) \\
(C, M) \rightarrow(M, A) \rightarrow(A, I) \rightarrow\end{array}$ \\
\hline 8 & $\mathrm{~L}$ & $\mathrm{~K}$ & 5,061547 & $\begin{array}{l}(I, G) \rightarrow(G, K) \rightarrow(K, L) \rightarrow \\
(L, H) \rightarrow(H, C) \\
(C, M) \rightarrow(M, A) \rightarrow(A, I) \rightarrow\end{array}$ \\
\hline 9 & $\mathrm{E}$ & $\mathrm{L}$ & 4 & $\begin{array}{l}(I, G) \rightarrow(G, K) \rightarrow(K, E) \rightarrow \\
(E, L) \rightarrow(L, H) \rightarrow(H, C) \\
(C, M) \rightarrow(M, A) \rightarrow(A, I) \rightarrow\end{array}$ \\
\hline 10 & $\mathrm{~N}$ & $\mathrm{E}$ & 2,513234 & $\begin{array}{l}(I, G) \rightarrow(G, K) \rightarrow(K, N) \rightarrow \\
(N, E) \rightarrow(E, L) \rightarrow(L, H) \rightarrow(H, C) \\
(C, M) \rightarrow(M, A) \rightarrow(A, I) \rightarrow\end{array}$ \\
\hline 11 & B & $\mathrm{N}$ & 1,286145 & $\begin{array}{l}(I, G) \rightarrow(G, K) \rightarrow(K, B) \rightarrow \\
(B, N) \rightarrow(N, E) \rightarrow(E, L) \rightarrow \\
(L, H) \rightarrow(H, C)\end{array}$ \\
\hline 12 & $\mathrm{~F}$ & $\mathrm{~L}$ & 0,683346 & $\begin{array}{l}(C, M) \rightarrow(M, A) \rightarrow(A, I) \rightarrow \\
(I, G) \rightarrow(G, K) \rightarrow(K, B) \rightarrow \\
(B, N) \rightarrow(N, E) \rightarrow(E, L) \rightarrow\end{array}$ \\
\hline
\end{tabular}




\begin{tabular}{|c|c|c|c|c|}
\hline Langkah & $\begin{array}{c}\text { Tambahan } \\
\text { anjungan }\end{array}$ & $\begin{array}{c}\text { Terdekat } \\
\text { dari }\end{array}$ & $\begin{array}{c}\text { Jarak } \\
\text { tambahan }\end{array}$ & Subtour sementara \\
\hline & & & & $(L, F) \rightarrow(F, H) \rightarrow(H, C)$ \\
\hline 13 & $\mathrm{D}$ & A & 4,502453 & $\begin{array}{l}(C, M) \rightarrow(M, D) \rightarrow(D, A) \rightarrow \\
(A, I) \rightarrow(I, G) \rightarrow(G, K) \rightarrow \\
(K, B) \rightarrow(B, N) \rightarrow(N, E) \rightarrow \\
(E, L) \rightarrow(L, F) \rightarrow(F, H) \rightarrow(H, C) \\
(C, M) \rightarrow(M, J) \rightarrow(J, D) \rightarrow \\
(D, A) \rightarrow(A, I) \rightarrow(I, G) \rightarrow\end{array}$ \\
\hline 14 & $\mathrm{~J}$ & - & 4,989778 & $\begin{array}{l}(G, K) \rightarrow(K, B) \rightarrow(B, N) \rightarrow \\
(N, E) \rightarrow(E, L) \rightarrow(L, F) \rightarrow \\
(F, H) \rightarrow(H, C)\end{array}$ \\
\hline
\end{tabular}

Melihat Tabel 5, penyelesaian TSP 14 anjungan menggunakan metode nearest insertion adalah $\quad(C, M) \rightarrow(M, J) \rightarrow(J, D) \rightarrow(D, A) \rightarrow(A, I) \rightarrow(I, G) \rightarrow(G, K) \rightarrow$ $(K, B) \rightarrow(B, N) \rightarrow(N, E) \rightarrow(E, L) \rightarrow(L, F) \rightarrow(F, H) \rightarrow(H, C) \quad$ dengan jarak 54,1972 .

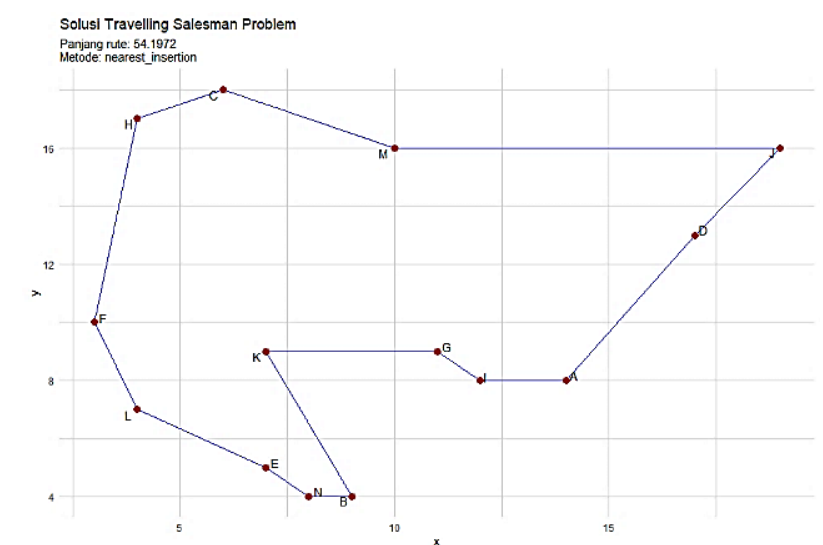

Gambar 2. TSP 14 Anjungan dengan Menggunakan Metode Nearest Insertion

\subsection{Penyelesaian TSP dengan Metode Cheapest Insertion}

Perbedaan dengan metode sebelumnya yaitu pemilihan kota yang akan disisipkan, metode nearest insertion berdasarkan jarak terdekat dengan kota yang sudah masuk subtour, sedangkan metode cheapest insertion berdasarkan jarak tambahan terkecil. Berikut diagram alir langkah metode cheapest insertion: 
P. S. Dewi et al.

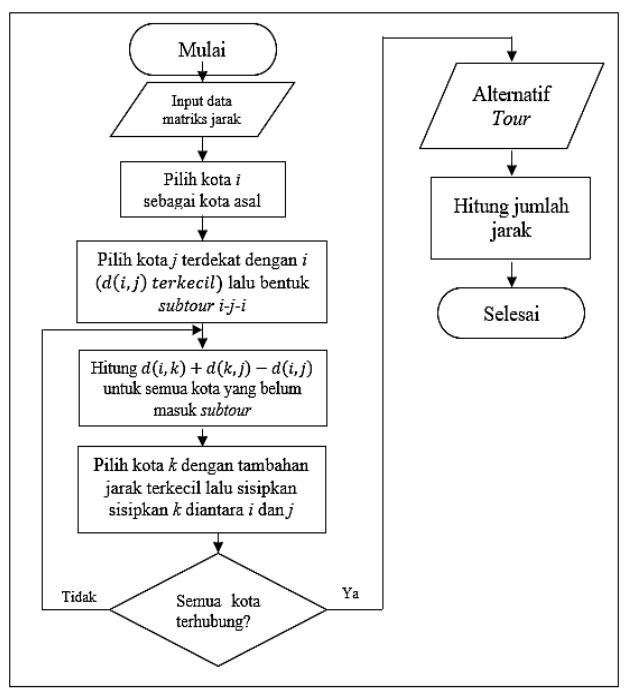

Gambar 3. Diagram Alir Metode Cheapest Insertion

Berikut contoh penyelesaian TSP dengan metode Cheapest Insertion menggunakan data jarak Tabel 2.

Langkah 1 Pada pembahasan kali ini dipilih anjungan $\mathrm{C}$ sebagai anjungan asal.

Langkah 2 Anjungan $\mathrm{H}$ terpilih sebagai anjungan terdekat dengan anjungan $\mathrm{C}$ karena memiliki jarak paling minimum yaitu 2,236068. Subtour sementara $C-H-C$ atau dapat ditulis $(C, H) \rightarrow(H, C)$.

Langkah 3 Memasukan anjungan $k \in\{A, B, D, E, F, I, J, K, L, M, N\}$ yang belum masuk dalam subtour. Adapun hasil langkah berikutnya ada pada Tabel 6 berikut.

Tabel 6. Penambah Subtour pertama pada Metode Cheapest Insertion

\begin{tabular}{ccc} 
Arc awal & $\begin{array}{c}\text { Arc yang akan } \\
\text { ditambahkan ke subtour }\end{array}$ & Jarak tambahan \\
\hline$(C, H)$ & $(C, A) \rightarrow(A, H)$ & $d_{C A}+d_{A H}-d_{C H}=24,023804$ \\
$(C, H)$ & $(C, B) \rightarrow(B, H)$ & $d_{C B}+d_{B H}-d_{C H}=26,010141$ \\
$(C, H)$ & $(C, D) \rightarrow(D, H)$ & $d_{C D}+d_{D H}-d_{C H}=23,448449$ \\
$(C, H)$ & $(C, E) \rightarrow(E, H)$ & $d_{C E}+d_{E H}-d_{C H}=23,171654$ \\
$(C, H)$ & $(C, F) \rightarrow(F, H)$ & $d_{C F}+d_{F H}-d_{C H}=13,379004$ \\
$(C, H)$ & $(C, G) \rightarrow(G, H)$ & $d_{C G}+d_{G H}-d_{C H}=18,689708$ \\
$(C, H)$ & $(C, I) \rightarrow(I, H)$ & $d_{C I}+d_{I H}-d_{C H}=21,467431$ \\
$(C, H)$ & $(C, J) \rightarrow(J, H)$ & $d_{C J}+d_{G H}-d_{C H}=25,950174$ \\
$(C, H)$ & $(C, K) \rightarrow(K, H)$ & $d_{C K}+d_{G H}-d_{C H}=15,363321$ \\
$(C, H)$ & $(C, L) \rightarrow(L, H)$ & $d_{C L}+d_{G H}-d_{C H}=18,944272$ \\
$(C, H)$ & $(C, M) \rightarrow(M, H)$ & $d_{C M}+d_{G H}-d_{C H}=8,318831$ \\
$(C, H)$ & $(C, N) \rightarrow(N, H)$ & $d_{C N}+d_{G H}-d_{C H}=25,507539$
\end{tabular}




\begin{tabular}{ccc} 
Arc awal & $\begin{array}{c}\text { Arc yang akan } \\
\text { ditambahkan ke subtour }\end{array}$ & Jarak tambahan \\
\hline$(H, C)$ & $(H, A) \rightarrow(A, C)$ & $d_{H A}+d_{A C}-d_{H C}=24,023804$ \\
$(H, C)$ & $(H, B) \rightarrow(B, C)$ & $d_{H B}+d_{B C}-d_{H C}=26,010141$ \\
$(H, C)$ & $(H, D) \rightarrow(D, C)$ & $d_{H D}+d_{D C}-d_{H C}=23,448449$ \\
$(H, C)$ & $(H, E) \rightarrow(E, C)$ & $d_{H E}+d_{E C}-d_{H C}=23,171654$ \\
$(H, C)$ & $(H, F) \rightarrow(F, C)$ & $d_{H F}+d_{F C}-d_{H C}=13,379004$ \\
$(H, C)$ & $(H, G) \rightarrow(G, C)$ & $d_{H G}+d_{G C}-d_{H C}=18,689708$ \\
$(H, C)$ & $(H, I) \rightarrow(I, C)$ & $d_{H I}+d_{I C}-d_{H C}=21,467431$ \\
$(H, C)$ & $(H, J) \rightarrow(J, C)$ & $d_{H J}+d_{J C}-d_{H C}=25,950174$ \\
$(H, C)$ & $(H, K) \rightarrow(K, C)$ & $d_{H K}+d_{K C}-d_{H C}=15,363321$ \\
$(H, C)$ & $(H, L) \rightarrow(L, C)$ & $d_{H L}+d_{L C}-d_{H C}=18,944272$ \\
$(H, C)$ & $(H, M) \rightarrow(M, C)$ & $d_{H M}+d_{M C}-d_{H C}=8,318831$ \\
$(H, C)$ & $(H, N) \rightarrow(N, C)$ & $d_{H N}+d_{N C}-d_{H C}=25,507539$
\end{tabular}

Melihat Tabel 6, dipilih $\operatorname{arc}(H, M)$ dengan $\operatorname{arc}(M, C)$ menggantikan $\operatorname{arc}(H, C)$ dengan jarak tambahan sebesar 8,318831. Subtour sementara yaitu $(C, H) \rightarrow$ $(H, M) \rightarrow(M, C)$. Belum semua anjungan masuk subtour, maka kembali seperti Langkah 3. Adapun hasil langkah berikutnya ada pada Tabel 7 berikut.

Tabel 7. Penambah Subtour pada Metode Cheapest Insertion

\begin{tabular}{|c|c|c|c|}
\hline Langkah & $\begin{array}{c}\text { Tambahan } \\
\text { anjungan }\end{array}$ & $\begin{array}{c}\text { Jarak } \\
\text { tambahan }\end{array}$ & Subtour sementara \\
\hline 4 & $\mathrm{~K}$ & 10,077014 & $(C, H) \rightarrow(H, K) \rightarrow(K, M) \rightarrow(M, C)$ \\
\hline 5 & $\mathrm{~F}$ & 2,65017 & $(C, H) \rightarrow(H, F) \rightarrow(F, K) \rightarrow(K, M) \rightarrow(M, C)$ \\
\hline 6 & $\mathrm{~L}$ & 2,644723 & $\begin{array}{l}(C, H) \rightarrow(H, F) \rightarrow(F, L) \rightarrow(L, K) \rightarrow \\
(K, M) \rightarrow(M, C)\end{array}$ \\
\hline 7 & $\mathrm{G}$ & 3,455295 & $\begin{array}{l}(C, H) \rightarrow(H, F) \rightarrow(F, L) \rightarrow(L, K) \rightarrow \\
(K, G) \rightarrow(G, M) \rightarrow(M, C)\end{array}$ \\
\hline 8 & I & 2,513234 & $\begin{array}{l}(C, H) \rightarrow(H, F) \rightarrow(F, L) \rightarrow(L, K) \rightarrow(K, I) \rightarrow \\
(I, G) \rightarrow(G, M) \rightarrow(M, C)\end{array}$ \\
\hline 9 & A & 3,748064 & $\begin{array}{l}(C, H) \rightarrow(H, F) \rightarrow(F, L) \rightarrow(L, K) \rightarrow(K, I) \rightarrow \\
(I, A) \rightarrow(A, G) \rightarrow(G, M) \rightarrow(M, C) \\
(C, H) \rightarrow(H, F) \rightarrow(F, L) \rightarrow(L, E) \rightarrow\end{array}$ \\
\hline 10 & $\mathrm{E}$ & 4 & $\begin{array}{l}(E, K) \rightarrow(K, I) \rightarrow(I, A) \rightarrow(A, G) \rightarrow(G, M) \rightarrow \\
(M, C)\end{array}$ \\
\hline 11 & $\mathrm{~N}$ & 2,513234 & $\begin{array}{l}(C, H) \rightarrow(H, F) \rightarrow(F, L) \rightarrow(L, E) \rightarrow \\
(E, N) \rightarrow(N, K) \rightarrow(K, I) \rightarrow(I, A) \rightarrow(A, G) \rightarrow \\
(G, M) \rightarrow(M, C)\end{array}$ \\
\hline 12 & B & 1,286145 & $\begin{array}{l}(C, H) \rightarrow(H, F) \rightarrow(F, L) \rightarrow(L, E) \rightarrow \\
(E, N) \rightarrow(N, B) \rightarrow(B, K) \rightarrow(K, I) \rightarrow(I, A) \rightarrow \\
(A, G) \rightarrow(G, M) \rightarrow(M, C)\end{array}$ \\
\hline 13 & $\mathrm{D}$ & 7,755808 & $\begin{array}{l}(C, H) \rightarrow(H, F) \rightarrow(F, L) \rightarrow(L, E) \rightarrow \\
(E, N) \rightarrow(N, B) \rightarrow(B, K) \rightarrow(K, I) \rightarrow(I, A) \rightarrow \\
(A, G) \rightarrow(G, D) \rightarrow(D, M) \rightarrow(M, C)\end{array}$ \\
\hline
\end{tabular}




\begin{tabular}{cccc} 
Langkah & $\begin{array}{c}\text { Tambahan } \\
\text { anjungan }\end{array}$ & $\begin{array}{c}\text { Jarak } \\
\text { tambahan }\end{array}$ & \multicolumn{1}{c}{ Subtour sementara } \\
\hline \multirow{2}{*}{14} & \multirow{2}{*}{$\mathrm{J}$} & 4,989778 & $\begin{array}{l}(C, H) \rightarrow(H, F) \rightarrow(F, L) \rightarrow(L, E) \rightarrow \\
(E, N) \rightarrow(N, B) \rightarrow(B, K) \rightarrow(K, I) \rightarrow(I, A) \rightarrow \\
\end{array}$ \\
& & & $(A, G) \rightarrow(G, D) \rightarrow(D, J) \rightarrow(J, M) \rightarrow(M, C)$
\end{tabular}

Melihat Tabel 7, penyelesaian TSP 14 anjungan menggunakan metode cheapest insertion adalah $(C, H) \rightarrow(H, F) \rightarrow(F, L) \rightarrow(L, E) \rightarrow(E, N) \rightarrow(N, B) \rightarrow(B, K) \rightarrow$ $(K, I) \rightarrow(I, A) \rightarrow(A, G) \rightarrow(G, D) \rightarrow(D, J) \rightarrow(J, M) \rightarrow(M, C)$ dengan jarak 58,42443 .

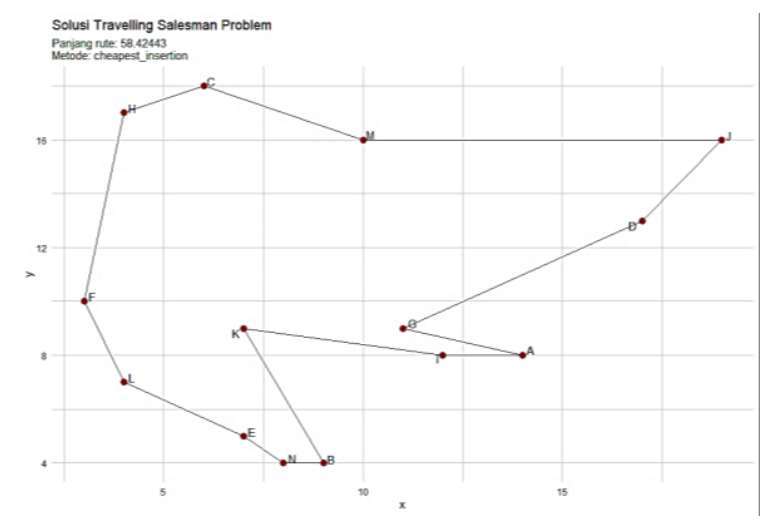

Gambar 4. TSP 14 Anjungan dengan Menggunakan Metode Cheapest Insertion

\subsection{Penyelesaian TSP dengan Metode Farthest Insertion}

Metode farthest insertion sama halnya metode nearest insertion namun berbeda pengambilan kota yaitu menggunakan kota terjauh bukan terdekat. Berikut diagram alir langkah metode farthest insertion:

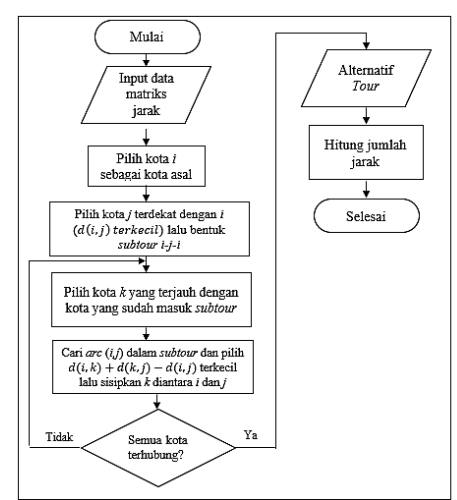

Gambar 5. TSP 14 Anjungan dengan Menggunakan Metode Nearest Insertion 
Berikut contoh penyelesaian TSP dengan metode Farthest Insertion menggunakan data jarak Tabel 2.

Langkah 1 Pada pembahasan kali ini dipilih anjungan $\mathrm{C}$ sebagai anjungan asal.

Langkah 2 Anjungan B terpilih sebagai anjungan terjauh dengan anjungan C karena memiliki jarak yang paling maksimum yaitu 14,317821. Subtour sementara $C-B-C$ atau dapat ditulis $(C, B) \rightarrow(B, C)$.

Langkah 3 Berikut ditunjukkan jarak antar anjungan lain dengan anjungan B dan C.

Tabel 8. Anjungan Terdekat Penambah Subtour Pertama Metode Farthest Insertion

\begin{tabular}{ccrccc} 
Jarak dari & Ke & \multicolumn{1}{c}{ Jarak } & Jarak dari & Ke & Jarak \\
\hline B & A & 6,403124 & C & A & 12,806248 \\
B & D & 12,041595 & C & D & 12,083046 \\
B & E & 2,236068 & C & E & 13,038405 \\
B & F & 8,485281 & C & F & 8,544004 \\
B & G & 5,385165 & C & G & 10,29563 \\
B & H & 13,928388 & C & H & 2,236068 \\
B & I & 5 & C & I & 11,661904 \\
B & J & 15,620499 & C & J & 13,152946 \\
B & K & 5,385165 & C & K & 9,055385 \\
B & L & 5,830952 & C & L & 11,18034 \\
B & M & 12,041595 & C & M & 4,472136 \\
B & N & 1 & C & N & 14,142136
\end{tabular}

Melihat Tabel 8, terpilih anjungan $\mathrm{J}$ sebagai anjungan terjauh dengan anjungan $\mathrm{B}$ karena memiliki jarak paling maksimum yaitu 15,620499, lalu anjungan $\mathbf{J}$ disisipkan dalam subtour dan dihitung menggunakan Persamaan (2) yang menghasilkan jarak tambahan terkecil.

Tabel 9. Arc Penambah Subtour Pertama pada Metode Farthest Insertion

\begin{tabular}{|c|c|c|}
\hline Arc awal & $\begin{array}{c}\text { Arc yang akan } \\
\text { ditambahkan ke subtour }\end{array}$ & \multicolumn{1}{|c|}{ Jarak tambahan } \\
\hline$(C, B)$ & $(C, J) \rightarrow(J, B)$ & $d_{C J}+d_{J B}-d_{C B}=14,455624$ \\
\hline$(B, C)$ & $(B, J) \rightarrow(J, C)$ & $d_{B J}+d_{J C}-d_{B C}=14,455624$ \\
\hline
\end{tabular}


Melihat Tabel 9, dipilih $\operatorname{arc}(C, J)$ dengan $\operatorname{arc}(J, B)$ menggantikan $\operatorname{arc}(C, B)$ dengan jarak tambahan sebesar 14,455624. Subtour sementara yaitu $(C, J) \rightarrow$ $(J, B) \rightarrow(B, C)$. Belum semua anjungan masuk subtour, maka kembali seperti Langkah 3. Adapun hasil langkah berikutnya ada pada Tabel 10 berikut.

Tabel 10. Penambah Subtour pada Metode Farthest Insertion

\begin{tabular}{|c|c|c|c|c|}
\hline Langkah & $\begin{array}{l}\text { Tambahan } \\
\text { anjungan }\end{array}$ & $\begin{array}{l}\text { Terjauh } \\
\text { dari }\end{array}$ & $\begin{array}{c}\text { Jarak } \\
\text { tambahan }\end{array}$ & Subtour sementara \\
\hline 4 & $\mathrm{~L}$ & $\mathrm{~J}$ & 17,492856 & $(C, J) \rightarrow(J, B) \rightarrow(B, L) \rightarrow(L, C)$ \\
\hline 5 & $\mathrm{~F}$ & $\mathrm{~J}$ & 0,525942 & $\begin{array}{l}(C, J) \rightarrow(J, B) \rightarrow(B, L) \rightarrow \\
(L, F) \rightarrow(F, C)\end{array}$ \\
\hline 6 & $\mathrm{E}$ & $\mathrm{J}$ & 0,010667 & $\begin{array}{l}(C, J) \rightarrow(J, B) \rightarrow(B, E) \rightarrow \\
(E, L) \rightarrow(L, F) \rightarrow(F, C)\end{array}$ \\
\hline 7 & $\mathrm{~N}$ & $\mathrm{~J}$ & 1,913858 & $\begin{array}{l}(C, J) \rightarrow(J, B) \rightarrow(B, N) \rightarrow \\
(N, E) \rightarrow(E, L) \rightarrow(L, F) \rightarrow(F, C) \\
(C, J) \rightarrow(J, B) \rightarrow(B, N) \rightarrow\end{array}$ \\
\hline 8 & $\mathrm{H}$ & $\mathrm{J}$ & 0,763132 & $\begin{array}{l}(N, E) \rightarrow(E, L) \rightarrow(L, F) \rightarrow \\
(F, H) \rightarrow(H, C)\end{array}$ \\
\hline 9 & $\mathrm{D}$ & $\mathrm{L}$ & 0,026647 & $\begin{array}{l}(C, J) \rightarrow(J, D) \rightarrow(D, B) \rightarrow \\
(B, N) \rightarrow(N, E) \rightarrow(E, L) \rightarrow \\
(L, F) \rightarrow(F, H) \rightarrow(H, C) \\
(C, J) \rightarrow(J, D) \rightarrow(D, B) \rightarrow\end{array}$ \\
\hline 10 & K & $\mathrm{J}$ & 4 & $\begin{array}{l}(B, N) \rightarrow(N, E) \rightarrow(E, K) \rightarrow \\
(K, L) \rightarrow(L . F) \rightarrow(F, H) \rightarrow(H, C) \\
(C, J) \rightarrow(J, D) \rightarrow(D, A) \rightarrow\end{array}$ \\
\hline 11 & A & $\mathrm{H}$ & 0,192481 & $\begin{array}{l}(A, B) \rightarrow(B, N) \rightarrow(N, E) \rightarrow \\
(E, K) \rightarrow(K, L) \rightarrow(L, F) \rightarrow \\
(F, H) \rightarrow(H, C)\end{array}$ \\
\hline 12 & M & $\mathrm{N}$ & 0,31919 & $\begin{array}{l}(C, M) \rightarrow(M, J) \rightarrow(J, D) \rightarrow \\
(D, A) \rightarrow(A, B) \rightarrow(B, N) \rightarrow \\
(N, E) \rightarrow(E, K) \rightarrow(K, L) \rightarrow \\
(L, F) \rightarrow(F, H) \rightarrow(H, C)\end{array}$ \\
\hline 13 & I & $\mathrm{H}$ & 0,596876 & $\begin{array}{l}(C, M) \rightarrow(M, J) \rightarrow(J, D) \rightarrow \\
(D, A) \rightarrow(A, I) \rightarrow(I, B) \rightarrow \\
(B, N) \rightarrow(N, E) \rightarrow(E, K) \rightarrow \\
(K, L) \rightarrow(L, F) \rightarrow(F, H) \rightarrow(H, C)\end{array}$ \\
\hline 14 & G & - & 1,799379 & $\begin{array}{l}(C, M) \rightarrow(M, J) \rightarrow(J, D) \rightarrow \\
(D, A) \rightarrow(A, I) \rightarrow(I, G) \rightarrow \\
(G, B) \rightarrow(B, N) \rightarrow(N, E) \rightarrow \\
(E, K) \rightarrow(K, L) \rightarrow(L, F) \rightarrow \\
(F, H) \rightarrow(H, C)\end{array}$ \\
\hline
\end{tabular}

Melihat Tabel 10, penyelesaian TSP 14 anjungan menggunakan metode farthest insertion adalah $\quad(C, M) \rightarrow(M, J) \rightarrow(J, D) \rightarrow(D, A) \rightarrow(A, I) \rightarrow(I, G) \rightarrow(G, B) \rightarrow$ 
$(B, N) \rightarrow(N, E) \rightarrow(E, K) \rightarrow(K, L) \rightarrow(L, F) \rightarrow(F, H) \rightarrow(H, C) \quad$ dengan jarak 54,1972 .

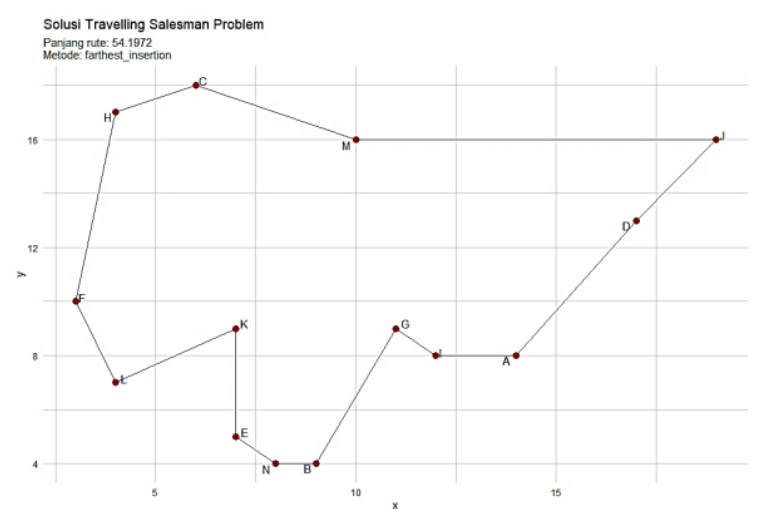

Gambar 6. TSP 14 Anjungan dengan Menggunakan Metode Farthest Insertion

\subsection{Program $R$ untuk Minimum TSP dari Tiga Metode Insertion}

Berikut langkah-langkah pemrograman $R$ untuk minimum TSP dari tiga metode insertion :

Langkah 1 Langkah awal pada pemrograman $R$ yaitu dengan mengeksport data excel ke data frame di $R$. Data awalnya disimpan dalam bentuk file penyimpanan CSV pada Microsoft Excel lalu dieksport menjadi data frame pada R dengan contoh nama 'mydata'.

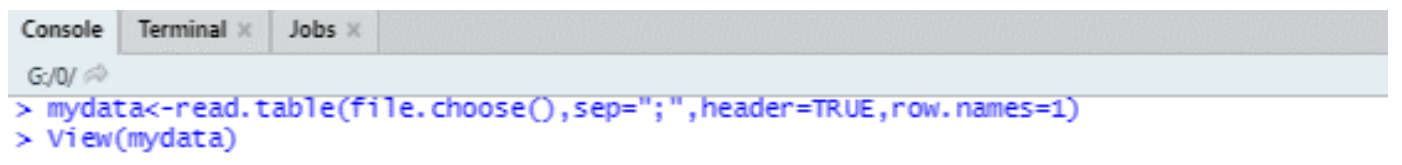

Gambar 7. Eksport Data Excel ke Data Frame di $R$

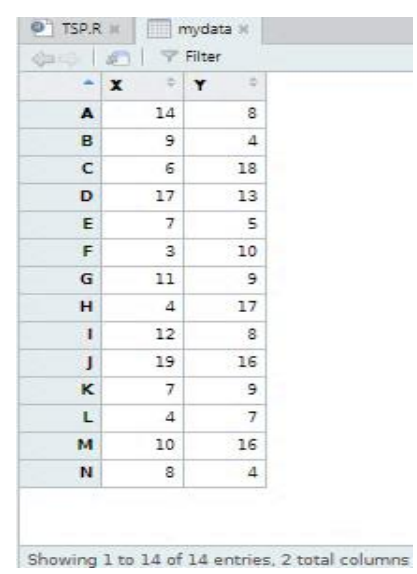

Gambar 8. Eksport Data Excel ke Data Frame di $R$ 
Langkah 2 Mengkonversi Data frame ke dalam bentuk matriks jarak menggunakan jarak Euclidean. Hasil matriks Euclidean 14 anjungan ada pada Gambar 9.

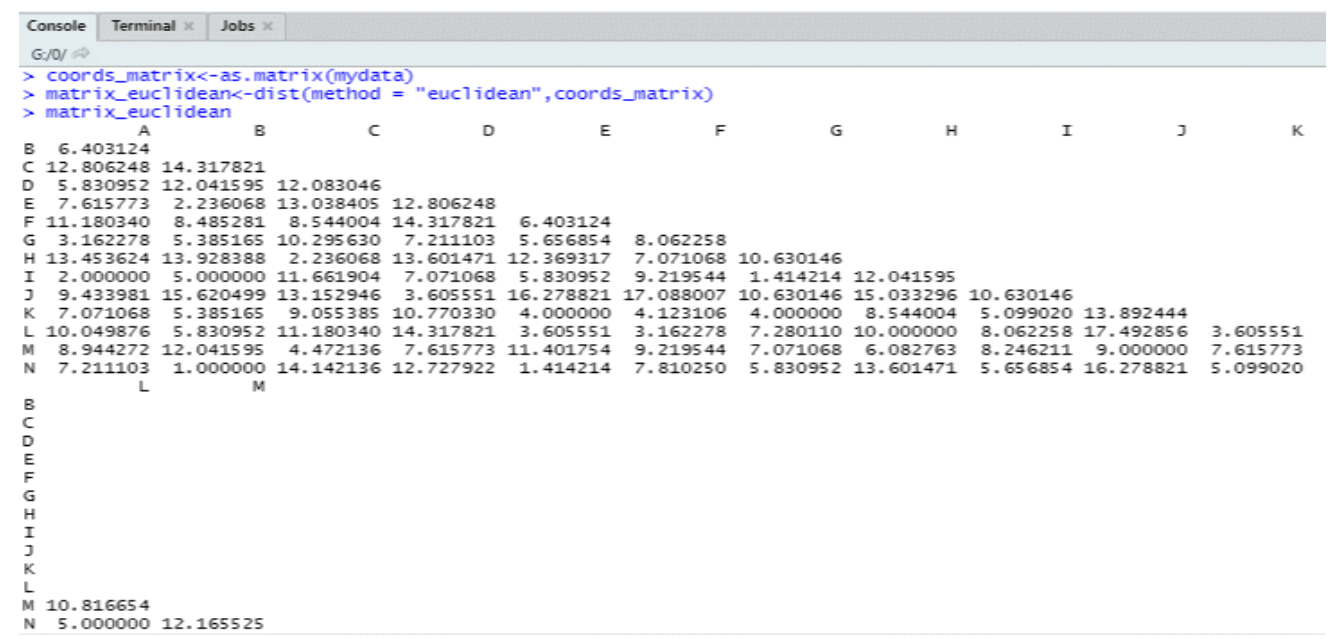

Gambar 9. Matriks Jarak Euclidean

Langkah 3 Matriks Euclidean dibuat menjadi objek TSP diikuti pendeskripsian metode yang akan digunakan yaitu metode cheapest insertion, metode nearest insertion dan metode farthest insertion. Pada program terdapat pilihan untuk menentukan titik awal bergerak dari anjungan mana sesuai kebutuhan.

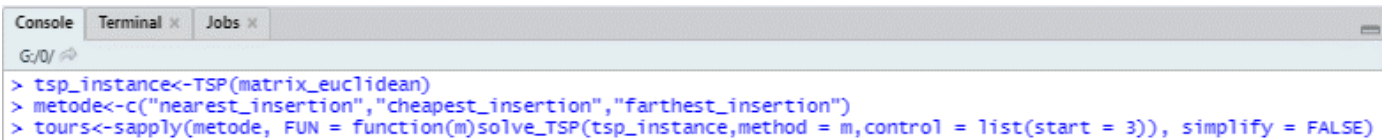

Gambar 10. Pembuatan Objek dan Metode TSP

Langkah 4 Mencari 'panjang_tur' untuk masing-masing metode lalu dicari mana metode yang yang mempunyai panjang tur/bobot paling minimal ('min_tur') dari ketiga metode. Hasil tour dapat berupa integer aupun data frame, namun untuk dibuat plot tour maka menggunakan hasil tour dalam bentuk data frame. 


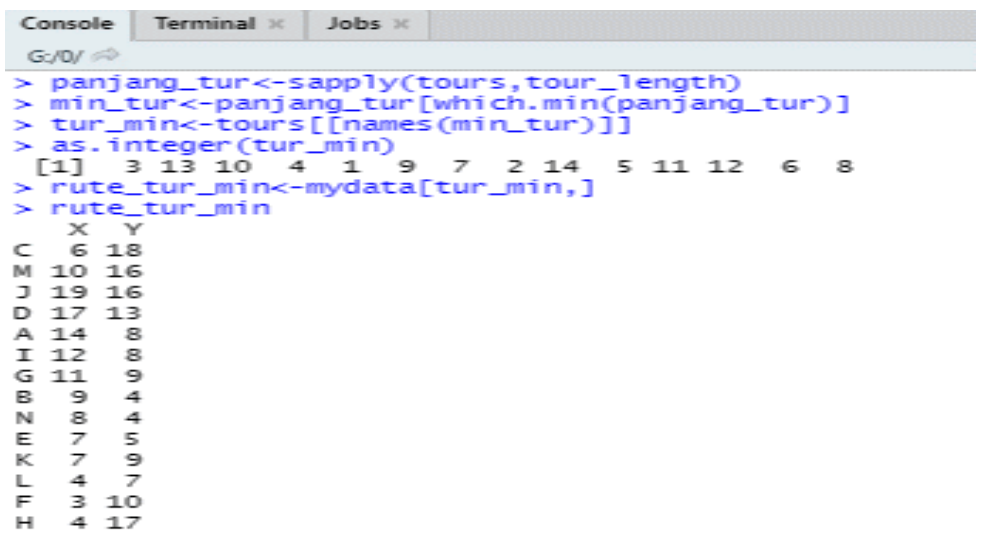

Gambar 11. Hasil Tour TSP

Langkah 5 Langkah terakhir yaitu membuat plot dari metode yang memiliki panjang tour/bobot paling minimum.

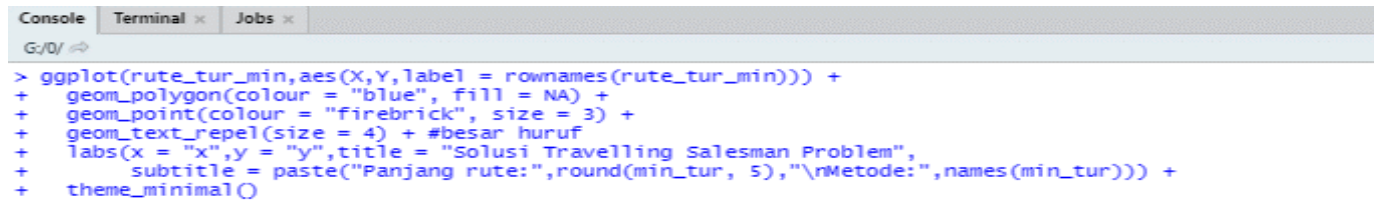

Gambar 12. Pembuatan Plot Hasil Tour TSP

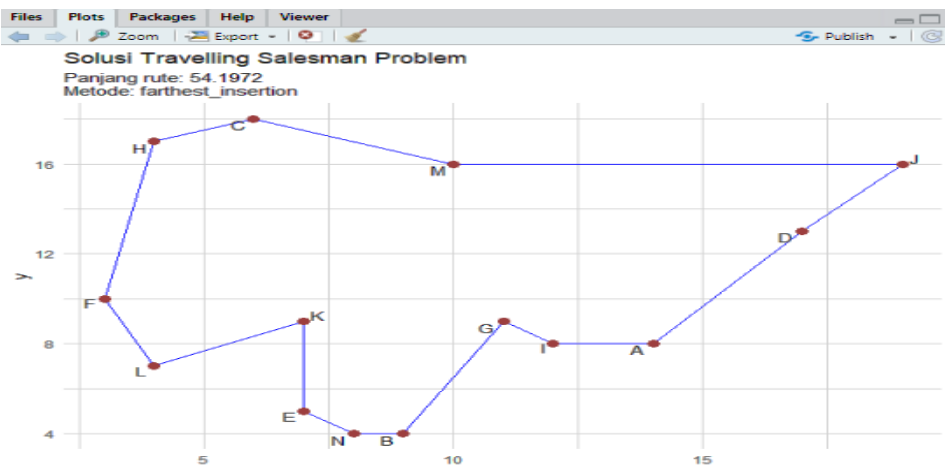

Gambar 13. Plot Hasil Tour TSP

Berdasarkan Gambar 13, penyelesaian Travelling Salesman Problem 14 Anjungan diketahui mempunyai panjang tour/bobot minimum sebesar 54,1972 dan tertulis metode farthest insertion yang artinya metode tersebut merupakan metode dengan bobot minimum dari ketiga metode untuk TSP 14 Anjungan. 


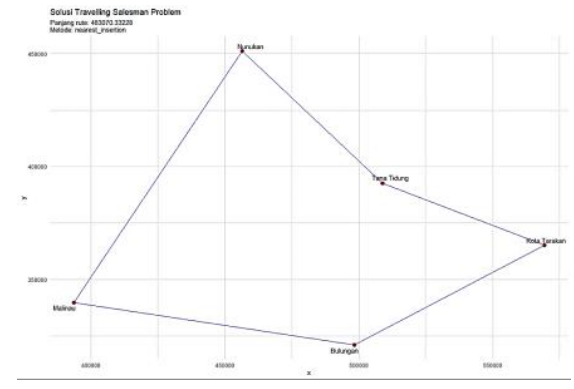

(a)

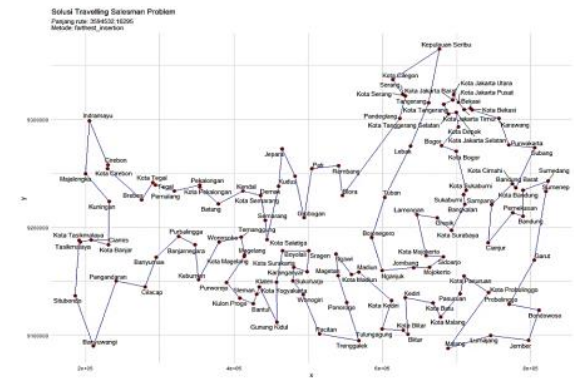

(b)

Gambar 14. TSP : (a) Provinsi Kalimantan Utara, (b) Pulau Jawa

Contoh lainnya yaitu menggunakan koordinat titik di Provinsi Kalimantan Utara dan Pulau Jawa. Berdasarkan Gambar 14(a), penyelesaian TSP Kalimantan Utara dengan 5 titik mempunyai panjang rute minimum sebesar 463.070,33228 m dan tertulis metode nearest insertion yang artinya metode tersebut merupakan metode dengan bobot minimum. Pada Gambar 14(b), penyelesaian TSP Pulau Jawa dengan 119 titik diketahui panjang rute sebesar 3.594.532,16295 m dan tertulis metode farthest insertion yang artinya metode tersebut merupakan metode dengan bobot minimum.

\section{KESIMPULAN DAN SARAN}

Berdasarkan hasil penelitian yang diperoleh, hasil TSP untuk data yang sama dengan menggunakan tiga metode insertion tidak selalu menghasilkan rute dan panjang rute/bobot yang sama. Sebagai saran, penyelesaian TSP dapat diperoleh dengan menggunakan metode insertion lain seperti arbitrary insertion dan nearest neighbor algorithm. Selain itu, dan dapat dikaji lebih lanjut tentang permasalahan riil di anjungan seperti adanya waktu penyaluran muatan, prioritas yang paling membutuhkan, biaya angkut, dan banyaknya permintaan barang untuk setiap anjungan yang akan dikunjungi.

\section{DAFTAR PUSTAKA}

Applegate, D. L., Bixby, R. E., Chvátal, V., dan Cook, W. J., The Traveling Salesman Problem : A Computational Study, Princeton University Press, New Jersey, 2006. 
Cormen, T. H., Leiserson, C. E., Rivest, R. L., dan Stein, C., Introduction to Algorithms, Second Edition, The MIT Press, London, 2001.

Dorigo, M. dan Stützle, T., Ant Colony Optimization, The MIT Press, London, 2004.

Goodaire, E. G., Discrete Mathematics with Graph Teory, Prentice Hall, Upper Saddle River, 1998.

Hahsler, M. dan Hornik, K., TSP-Infrastructure for the Travelling Salesperson Problem, Journal of Statistical Software, 32(2) (2007), 5-10.

Hahsler, M. dan Hornik, K., TSP-Infrastructure for the Travelling Salesperson Problem, Cran R Project Org, Package 'TSP, 2020.

Kusrini dan Istiyanto, J. E., Penyelesaian Travelling Salesman Problem dengan Algoritma Cheapest Insertion Heuristics dan Basis Data, Journal Informatika, 8(2) (2007), 110-111.

Munir, R., Matematika Diskrit, Edisi Ketiga, Informatika Bandung, Bandung, 2010.

Prawidya, A., Pramono, B., dan Aksara, L. B., Travelling Salesman Problem (TSP) untuk Menentukan Rute Terpendek bagi Kurir Kota Kendari Menggunakan Algoritma Greedy Berbasis Android, 3(1) (2017), 95-106.

Rosen, K. H., Discrete Mathematics and Its Application, Edisi Kelima, WCB McGraw-Hiil, New York, 2003.

Rosenkrantz, D. J., Stearns, R. E., dan Lewis, P. M., An Analysis of Several Heuristics for the Traveling Salesman Problem, SIAM Journal on Computing, 6(3) (1977), 570-577.

Wilson, R. J. dan Watkins, J. J., Graphs : An Introductory Approach, John Willey and Sons, New York, 1990.

Yuan Ze University, The Traveling Salesman Problem (TSP) and its solving algorithm, http://logistics.iem.yzu.edu.tw/Courses/1041/TSP\%20Problem.pdf, diakses pada 13 April 2020. 